\title{
EFFECT OF DIFFERENT IRRIGATING PROTOCOLS ON THE BOND STRENGTH OF THE ACTIV GUTTA PERCHA ROOT CANAL OBTURATION SYSTEM (COMPARATIVE IN VITRO STUDY)
}

\author{
Shaimaa H Ismail ${ }^{l} B D S$, Ashraf M Zaazou ${ }^{2} P h D$, Nihal A Leheta ${ }^{3} P h D$, \\ Seham A Hanafy ${ }^{4} P h D$
}

\begin{abstract} dentin surfaces.

OBJECTIVES: evaluate the effect of different irrigating protocols used as final rinse on the bond strength of the ActiV gutta percha. and one-way ANOVA test. than that of the coronal sections. The failure mode was predominantly cohesive in groups II and III and adhesive in groups I and IV. mode.

KEYWORDS: Endodontics, ActiV GP, Chlorhexidine, MTAD, EDTA, Push out bond strength.

1- Instructor at the Conservative Dentistry Department, Faculty of Dentistry, Alexandria University, Alexandria, Egypt

2- Professor of Endodontics, Faculty of Dentistry, Alexandria University, Alexandria, Egypt.

3- Lecturer of Endodontics, Faculty of Dentistry, Alexandria University, Alexandria, Egypt.

4- Professor of Dental Biomaterials Faculty of Dentistry, Alexandria University, Alexandria, Egypt.
\end{abstract}

INTRODUCTION: Different irrigations may cause alteration in the composition of dentin, thereby affecting the adhesion of materials to MATERIALS AND METHODS: Forty extracted single rooted lower premolars were used. Teeth were decoronated to standardize the root length to $15 \mathrm{~mm}$. The canals were instrumented using OneShape rotary system. Teeth were irrigated with $2.5 \%$ sodium hypochlorite then divided into four parallel groups according to the final rinse $(\mathrm{n}=10)$. GroupI: $10 \mathrm{ml} 17 \%$ Ethylene diaminetetraacetic acid, followed by $10 \mathrm{ml}$ of $2.5 \% \mathrm{NaOCL}$; GroupII: $10 \mathrm{ml}$ of $1.3 \%$ mixture of a tetracycline isomer, an acid and detergent (MTAD); GroupIII: $10 \mathrm{ml}$ of $2 \%$ chlorhexidine gluconate; GroupIV: $10 \mathrm{ml} 2.5 \% \mathrm{NaOCL}$ (control). All the root canals were filled using ActiV GP. Slicing was done at the coronal and middle thirds for push-out test to measure bond strength. Then failure mode was evaluated under stereomicroscope. Data were analysed using t-test

RESULTS: Group III yielded significantly the highest mean push-out bond strength $(2.91 \pm 0.79 \mathrm{MPa})$, followed by group II ( $2.39 \pm 0.89 \mathrm{MPa})$, then group IV $(1.80 \pm 0.61 \mathrm{MPa})$ and finally group I $(1.61 \pm 0.52 \mathrm{MPa})$. The bond strength values of the middle sections were significantly higher

CONCLUSIONS: CHX and MTAD increased the bond strength of ActiV GP, while EDTA decreased the bond strength. The push out bond strength values were affected by the location of root segment. There was correlation between the push out bond strength values and the failure

\section{INTRODUCTION:}

Successful endodontic therapy depends on thorough chemomechanical preparation of the root canal system as well as three-dimensional obturation. A key part of root canal treatment is the canal instrumentation, including shaping the root canals in a manner that allows rinsing with irrigation. Rotary instrumentation aids in effectively cleaning and shaping the root canals, but may result in irregular smear layer plugging the dentinal tubules (1).

Sodium hypochlorite (Clorox, Egypt) is the most widely used irrigant in root canal treatment and is considered the gold standard irrigant. It is an effective antimicrobial agent and excellent organic solvent for vital and necrotic tissues (2). However, it is highly irritating to periapical tissues and its capacity to remove the smear layer from the root dentin appears to be limited.

Ethylene diaminetetraacetic acid (CanalPro EDTA, Colltène Whaledent, Germany) is generally accepted as the most effective chelating agent in endodontic therapy. It is used to enlarge root canals, remove the smear layer, and prepare the dentinal walls for a better adhesion of filling materials (3).

The alternating use of EDTA and $\mathrm{NaOCl}$ has the benefit to remove both the organic and inorganic components of the smear layer (4) but it lacks sustained antimicrobial capacity.

Chlorhexidine gluconate (CHX endo, Prevest Dent Pro. Germany) has been suggested as an alternative irrigating solution that could replace $\mathrm{NaOCl}$. Its antibacterial action would persist in root canal from 8-12 weeks (5), however, it has got no tissue dissolution ability.

Another endodontic irrigant MTAD (Biopure, Dentsply Tulsa, USA) which has been shown to be clinically effective and biocompatible. MTAD is a mixture of $4.25 \%$ citric acid, $3 \%$ doxycycline hyclate and $0.5 \%$ Tween 80 . It is the first endodontic irrigant, which is able to remove mineral part of smear layer and sustained antibacterial activity (6). It has been recommended as a final rinse after initial irrigation with $\mathrm{NaOCl}$.

Among the required physical properties of filling materials, adhesion was found to be a very desirable property in root canal cements. Ideal endodontic cement must seal the root canal space and should adhere to both the gutta-percha core and canal wall.

So manufacturers have introduced adhesive dentistry to the field of endodontics with a specific focus on obtaining a "monoblock" in which the core material, sealing agent, and the root canal dentin form a single cohesive unit to create a hermetic seal within the root canal space which is the goal of endodontic treatment (7). ActiV gutta percha (Brasseler USA, Savannah, GA) is a system that utilizes new improved glass ionomer technology. The system comprises glass ionomer impregnated and coated gutta-percha cones. In addition, the good chemical bonding of the ActiV GP (a diffusion-based adhesion) would have developed by ion exchange between the glass-ionomer and the tooth surface. 
Because of its multiple ionized carboxylate groups, the polyalkenoic acid within this sealer has been shown to have a chelating reaction with the calcium ions of the dentin matrix (8).

Few studies have investigated the degree of bonding and adaptation of this material to root canal dentin. So this study was designed to compare the effect of different irrigating protocols on the bond strength of ActiV GP system using push out test and investigate the mode of failure.

The null hypothesis tested in this study was that the use of different endodontic irrigants has no effect on the bond strength of the obturation materials.

\section{MATERIALS AND METHODS:}

Forty recently extracted human single-rooted mandibular premolar teeth were used in this study. The teeth were thoroughly cleaned from any soft tissue or calculus deposition, then they were stored in isotonic saline solution at room temperature all over the study.

\section{Endodontic preparation of the teeth:}

The crowns of all specimens were cut transversally with double-faced diamond disc to obtain a $15 \mathrm{~mm}$ root length for standardization. Working lengths were then established by inserting a \#10 K-file (MicroMega, Besancon, France) to the root canal terminus until it became visible through the apical foramen and subtracting $1 \mathrm{~mm}$. Root canals with initial apical file \#15 K-file were selected to standardize the canal diameter. Instrumentation was continued using OneShape single file (MicroMega, Besancon, France) ${ }^{\#} 25$ 0.06 taper that was introduced into the canals, activated by Endo Mate AT electric motor (NSK Company, Japan). Finally, instrumentation was completed manually using $\mathrm{H}$ files till \#60 in step-back technique.

All the teeth were irrigated with $20 \mathrm{ml}$ of $2.5 \% \mathrm{NaOCL}$ using 27- gauge side vented needle throughout the instrumentation. The needle was passively placed up to 2 $\mathrm{mm}$ from the working length without binding.

\section{Grouping:}

Then the teeth were randomly divided into four parallel groups according to the final rinse $(\mathrm{n}=10)$, as follow: Group I: $10 \mathrm{ml} 17 \%$ EDTA; followed by $10 \mathrm{ml}$ of $2.5 \% \mathrm{NaOCl}$. Group II: $10 \mathrm{ml} 1.3 \% \mathrm{MTAD}$. Group III: $10 \mathrm{ml}$ of $2 \% \mathrm{CHX}$. Group IV: $10 \mathrm{ml} 2.5 \% \mathrm{NaOCl}$.

All the teeth were irrigated with the final rinse for 15 minutes using 27-gauge side vented needle.

\section{Obturation:}

The canals were dried with tapered paper points then filled using ActiV GP by cold lateral compaction technique. The glass-ionomer sealer was mixed according to manufacturer's instructions. It was placed into the canal walls by a matching hand file which was taken to the full working length. An ActiV GP master cone size 25, 0.06 taper was dipped in the sealer and slowly inserted into the canal to the working length, then an appropriate hand spreader was inserted, rotated, and withdrawn. Then the obturation process was completed using accessory ActiV GP cones, until the canal was completely obturated. Excess gutta-percha was seared using a heated instrument. A layer of the sealer was put on the top as recommended by the manufacturer.

The roots were coded and placed in $100 \%$ relative humidity at $37^{\circ} \mathrm{C}$ for 1 week to ensure complete setting of the sealer.

\section{Sample Slicing and Subgrouping:}

Each root was then embedded in a custom-made split ring copper mold. After setting of the resin, two horizontal sections of $2 \mathrm{~mm}$ thickness were cut from coronal and middle thirds perpendicular to the long axis of the root using circular diamond disk as shown in figure (1). The apical $5 \mathrm{~mm}$ of each root was discarded. Two slices were obtained from each root, the dimensions of each root slice were measured with a digital caliper to within $0.01 \mathrm{~mm}$. This resulted in 20 horizontal sections per group with a total number of 80 sections for the four experimental groups. As each group was divided into two subgroups: subgroup a (coronal sections) and subgroup $\mathrm{b}$ (middle sections).

Each section was then coded and measured for apical and coronal diameters of the obturated area.

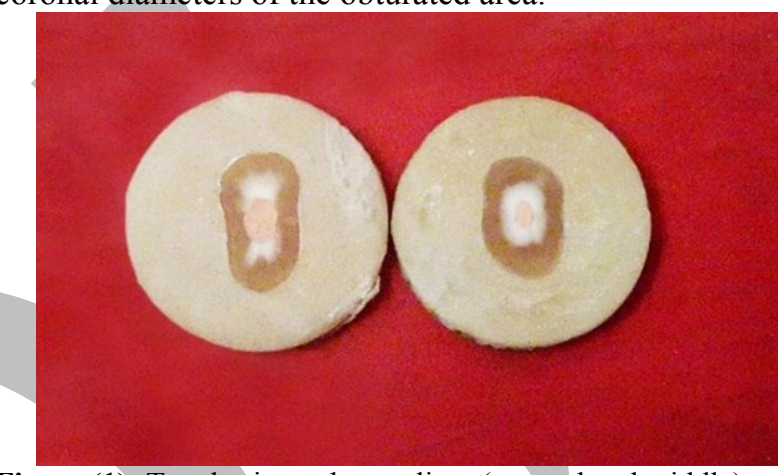

Figure (1): Two horizontal root slices (coronal and middle).

\section{Push out test:}

Each root section was subjected to a compressive load via a universal testing machine (Comten Industries, Inc, USA) at a crosshead speed of $0.5 \mathrm{~mm} / \mathrm{min}$ using custom cylindrical plunger with specially designed sizes for each root section. $0.8 \mathrm{~mm}$ diameter for the coronal sections and $0.5 \mathrm{~mm}$ diameter for the middle sections. The plunger tip was positioned so that it only contacted the filling material and avoided contact with the sealing agent and root canal walls. The push-out force was applied in an apicocoronal direction until bond failure occurred, which was manifested by extrusion of the obturation material and a sudden drop along the load deflection. The maximum failure load was recorded in newtons and was used to calculate the push-out bond strength in megapascals according to the following formula (9):

Push-out bond strength $(\mathrm{MPa})=$ Maximum load $(\mathrm{N})$

Adhesion area of root canal filling $\mathrm{mm}^{2}$

The adhesion (bonding) surface area of each section was calculated as:

$\Pi\left(r_{1}+r_{2}\right) \sqrt{ }\left\{\left(r_{1}-r_{2}\right)^{2}+h^{2}\right\}$, where $\pi$ is the constant $3.14, r_{1}$ is the smaller radius, $r_{2}$ is the larger, and $h$ is the thickness of the section in $\mathrm{mm}$.

\section{Determination of the mode of failure:}

After the push out test, the debonded surfaces of the slices were examined under the Olympus stereomicroscope at $\times$ 50 magnification to detect the mode of failure between the sealer and dentine. Each sample was evaluated and placed into one of 3 failure modes:

- Adhesive failure, at the sealer-dentin interface.

- Cohesive failure, within the filling material.

- Mixed failure, including both adhesive and cohesive failures. 


\section{STATISTICAL ANALYSIS:}

The collected data was fed to statistical software IBM SPSS version 20. All statistical analysis was done using two tailed tests and alpha error of $0.05 \mathrm{P}$ value less than or equal to 0.05 was considered to be statistically significant.

The data were statistically analyzed. The mean and standard deviation of the bond strength data were compared using One Way ANOVA test while the mode of failure data was analyzed via Mont Carlo exact test.

\section{RESULTS:}

Group III (CHX) yielded significantly the highest mean push out bond strength $(2.91 \pm 0.79 \mathrm{MPa})$, followed by group II (MTAD) $(2.39 \pm 0.89 \mathrm{MPa})$, then group IV $(\mathrm{NaOCl})(1.80 \pm 0.61 \mathrm{MPa})$ and finally group I (EDTA then $\mathrm{NaOCl})(1.61 \pm 0.52 \mathrm{MPa})$, as shown in table (1) and figure (2).

Results for the mode of failure showed that the predominant mode of failure in groups II (MTAD) and III (CHX) was cohesive. While adhesive failure was the predominant failure mode in group I (EDTA then $\mathrm{NaOCl}$ ). Group IV $(\mathrm{NaOCl})$ showed the three modes of failure with near percentages as shown in figure (3). Table (2) and figure (4) showed comparison between different modes of failure of the four groups with their subgroups.

Table (1): Comparison between the push out bond strength of different groups (MPa).

\begin{tabular}{|c|cc|cc|c|}
\hline \multirow{2}{*}{ Group } & \multicolumn{3}{|c|}{ Bond strength(MPa) } & F (P) \\
\cline { 2 - 5 } & Minimum & Maximum & Mean & SD & \\
\hline $\begin{array}{c}\text { Group I } \\
\text { (EDTA \& } \\
\text { NaOCl) }\end{array}$ & 0.83 & 2.52 & 1.61 & 0.52 & \\
\hline $\begin{array}{c}\text { Group II } \\
\text { (MTAD) }\end{array}$ & 1.08 & 3.74 & 2.39 & 0.89 & \multirow{2}{*}{14.2} \\
\hline $\begin{array}{c}\text { Group } \\
\text { III(CHX) }\end{array}$ & 1.25 & 4.18 & 2.91 & 0.79 & \\
\hline $\begin{array}{c}\text { Group } \\
\text { IV(NaOCl) }\end{array}$ & 0.86 & 2.98 & 1.80 & 0.61 & \\
\hline
\end{tabular}

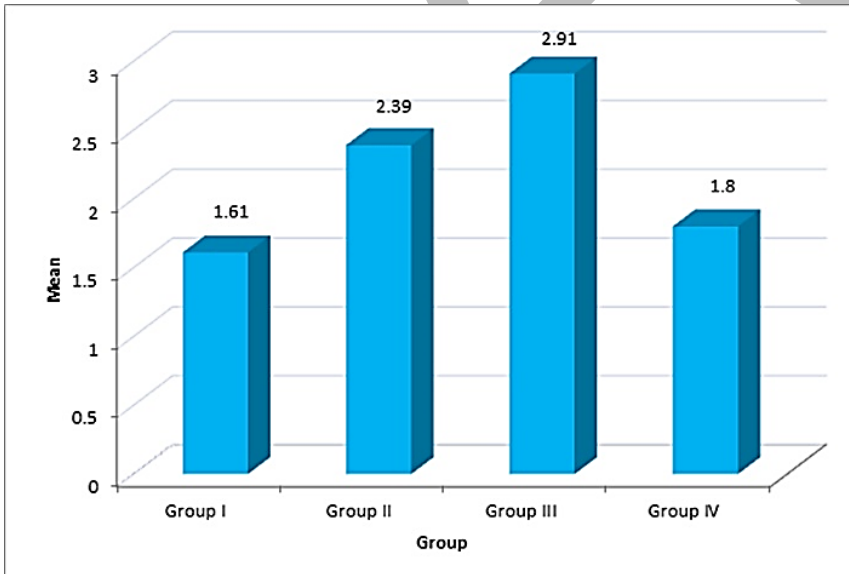

Figure (2): Comparison between the different groups regarding the mean push out bond strength (MPa).

\section{DISCUSSION:}

Dentin surface treatment with different irrigation regimens may cause alteration in the chemical and structural composition of human dentin, thereby changing its permeability and solubility characteristics $(10,11)$ and hence affecting the adhesion of materials to dentin surfaces.

Therefore, this study was conducted to compare the effect of different irrigation protocols used as final rinse on the bond strength of the ActiV gutta percha root canal obturation system using the push out test and to determine the failure mode using stereomicroscopic evaluation.

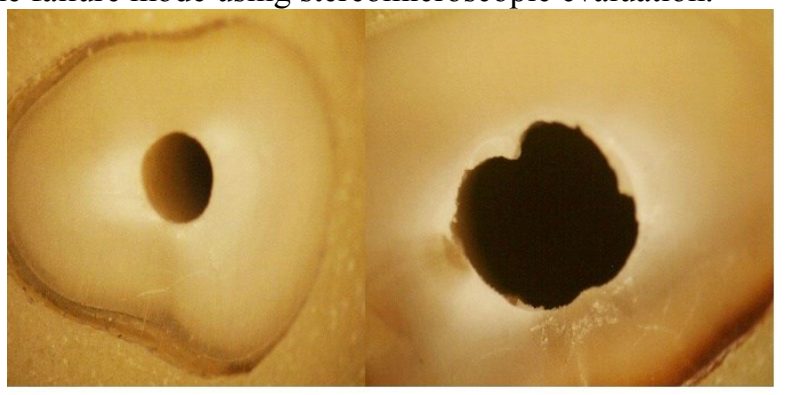

(A)

(B)

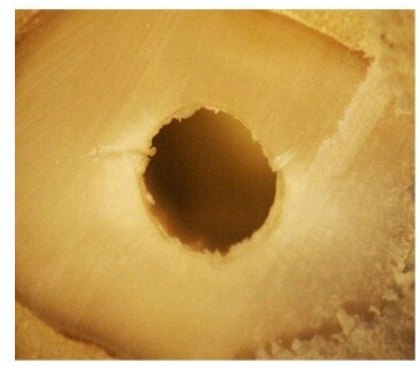

(C)

Figure (3): Stereomicroscopic picture of different failure modes. a: Adhesive, b: Mixed, c: Cohesive failures.

Extracted human teeth were used in the current study to simulate the clinical conditions. This was in agreement with Farag et al (12), Hashem et al (13), Dinesh et al (14) and Naser and Al-Zaka (15).

Single rooted teeth (16) with nearly similar apical diameters, root length $(15 \mathrm{~mm} \pm 1)(17)$ and ovoid root canal cross sections were selected for standardization.

In the present study One Shape single file system was selected in the endodontic preparation of teeth as recent studies have proved that One Shape's flexibility and unique downward movement ensures a highly effective apical progression with minimal fatigue along the length of the file (18).

Specimen preparation for the push out test was done by cutting two horizontal sections from the coronal and middle thirds with $2 \mathrm{~mm}$ thickness (16) to withstand the applied forces without premature fracture or debonding. This was also revealed by Farag et al (12), Hashem et al (13) and Dinesh et al (14). On the other hand, Rocha et al (17) used $0.8 \mathrm{~mm}$ thick slices, but $2 \mathrm{~mm}$ slices were preferred in this work.

Different tests have been reported for bond strength evaluation which include shear strength, microtensile and even pull-out or push-out tests have been described as reproducible and effective (19). In the current study, it was preferred to use the push out bond strength to evaluate the bond strength of ActiV GP. As it was revealed by Ungor et al (20) that it allows an accurate standardization of the specimens and obturation materials to be evaluated even when bond strengths are low at different levels of root canal walls. It also provides smaller adhesive areas and thus more uniform stress distribution on the adhesive interface (21). 
Table (2): Comparison between different subgroups regarding the mode of failure.

\begin{tabular}{|c|c|c|c|c|c|c|c|c|c|c|c|c|c|c|c|c|}
\hline \multirow{3}{*}{ Mode of Failure } & \multicolumn{4}{|c|}{$\begin{array}{c}\text { GroupI } \\
\text { (EDTA\&NaOCl) }\end{array}$} & \multicolumn{4}{|c|}{$\begin{array}{l}\text { GroupII } \\
\text { (MTAD) }\end{array}$} & \multicolumn{4}{|c|}{$\begin{array}{l}\text { Group III } \\
\text { (CHX) }\end{array}$} & \multicolumn{4}{|c|}{$\begin{array}{l}\text { GroupIV } \\
\text { (NaOCl) }\end{array}$} \\
\hline & \multicolumn{2}{|c|}{$\begin{array}{c}\mathrm{A} \\
\text { (coronal) }\end{array}$} & \multicolumn{2}{|c|}{$\begin{array}{c}\mathrm{B} \\
\text { (middle) }\end{array}$} & \multicolumn{2}{|c|}{$\begin{array}{c}\mathrm{A} \\
\text { (coronal) }\end{array}$} & \multicolumn{2}{|c|}{$\underset{\text { (middle) }}{\mathrm{B}}$} & \multicolumn{2}{|c|}{$\begin{array}{c}\mathrm{A} \\
\text { (coronal) }\end{array}$} & \multicolumn{2}{|c|}{$\begin{array}{c}\mathrm{B} \\
\text { (middle) }\end{array}$} & \multicolumn{2}{|c|}{\begin{tabular}{c|}
$\mathrm{A}$ \\
(coronal)
\end{tabular}} & \multicolumn{2}{|c|}{$\underset{\text { (middle) }}{\mathrm{B}}$} \\
\hline & No & $\%$ & No & $\%$ & No & $\%$ & No & $\%$ & No & $\%$ & No & $\%$ & No & $\%$ & No & $\%$ \\
\hline Adhesive & 6 & 60 & 7 & 70 & 1 & 10 & 1 & 10 & 1 & 10 & 0 & 0 & 4 & 40 & 4 & 40 \\
\hline Cohesive & 1 & 10 & 2 & 20 & 5 & 50 & 6 & 60 & 8 & 80 & 9 & 90 & 3 & 30 & 4 & 40 \\
\hline Mixed & 3 & 30 & 1 & 10 & 4 & 40 & 3 & 30 & 1 & 10 & 1 & 10 & 3 & 30 & 2 & 20 \\
\hline$M C P$ & & 0.4 & & & & 0.8 & 90 & & & 0.58 & 589 & & & & 842 & \\
\hline
\end{tabular}

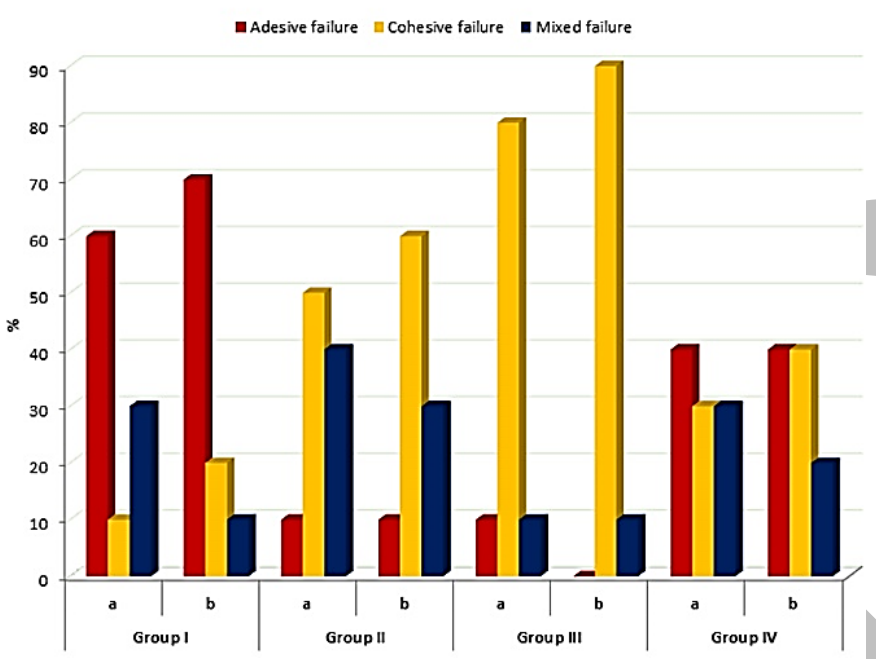

Figure (4): Comparison between different modes of failure in all subgroups.

The current results disproved the null hypothesis that the use of different endodontic irrigants has no effect on the bond strength of the obturation materials.

In the present study, it was found that the irrigation regimens influenced the bond strength of the tested obturation system. Using $17 \%$ EDTA in group I significantly decreased the bond strength of ActiV GP. This was in accordance to Attal et al (22) and Dogen Buzoglut et al (23). They reported that EDTA significantly decreases the wettability of dentinal wall which prohibites the adhesion of hydrophilic materials as ActiV GP. They also attributed this to the removal of the smear layer by EDTA which depleted calcium ions necessary for the ActiV GP bonding.

On the other hand, other studies found that final irrigation with EDTA resulted in higher bond strength values. This variation could be attributed to the use of different obturation materials like gutta percha /AH plus sealer (24, 25). This is because EDTA significantly decreases surface energy providing a suitable dentin substrate for the adhesion of hydrophobic materials as the resinous $\mathrm{AH}$ plus. Furthermore, the effective removal of the smear layer by EDTA allows for the extension of the resin into the open dentinal tubules, creating efficient microretention.

Group II (MTAD group) has enhanced the bond strength of ActiV GP and this was in accordance to a study made by Hashem et al (13). This could be due to the presence of Tween 80 detergent, a constituent of MTAD. It increases dentin surface energy and wettability, hence increasing intertubular dentin permeability which provided a good adhesion surface for hydrophilic materials like ActiV GP.

On the contrary, Ravikumar et al (26) found that MTAD could have negatively affected the adhesion of resinous obturation materials as AH Plus. As MTAD permits increased dentin surface energy which was a poor substrate for adhesion of hydrophobic materials. This was in agreement with Shokouhinejad et al (27).

The mean bond strength values obtained after MTAD irrigation was significantly greater than that of EDTA group. This might be explained by the fact that MTAD effectively removes the smear layer with less dental erosion than EDTA and without any adverse effects on flexure strength and modulus of elasticity of dentin, unlike EDTA as ravealed by Singh et al (28).

According to the present results, the use of $\mathrm{CHX}$ as a final rinse in group III significantly increased the bond strength of ActiV GP. This could be explained by the presence of surfactant in the CHX irrigant which increases the dentin surface energy and wettability as revealed by Agrawal et al (29). Furthermore, CHX has nonacidic and nonchelator properties with little decalcifying effect on the root dentin and enhances the cationic charging of the dentin surface, thus increasing the reaction of polycarboxylic group of the glass ionomer as revealed by Perdigao et al (30).

On the other hand, other researchers found that final rinse with $\mathrm{CHX}$ resulted in a significant decrease in the bond strength of gutta percha /AH Plus $(4,13)$. This could be attributed to the effect of $\mathrm{CHX}$ in increasing the dentin permeability which prohibited the penetration of hydrophobic $\mathrm{AH}$ Plus sealer and interfering with its adhesion.

Comparison between group I and group IV (control group) revealed that the use of EDTA before $\mathrm{NaOCl}$ decreased the mean bond strength values of ActiV GP compared to the use of $\mathrm{NaOCl}$ alone. This was correlated to a previous study made by Lalh et al (31). Their explanation was that $\mathrm{NaOCI}$ dissolves the collagen and other organic substances of the smear layer so it becomes more porous which enables the polyacrylic acid of the GIC sealer to induce a mild demineralization of the smear layer and this helps in the chemical interaction with the dentin. In addition, the $\mathrm{NaOCl}$-altered smear layer enhances the sealer penetration into the dentinal tubules to increase the micromechanical.

Regarding the location of the root segment, the current results showed that the bond strength values for middle slices were higher than that of coronal slices in all groups as revealed by Baldissera et al (32). Their reason was that the section diameter of the root canal was inversely proportional to bond strength values i.e the greater the section diameter, the lower the resistance to dislodgment.

These findings disagreed with Naser and Al-Zaka (15) Nagas et al (33) and Al-Hamed et al (34). They found that the bond strength values decreased from coronal to apical direction. They referred this to inadequate volume or penetration of the irrigation and final rinse solutions into the apical portion of the canal (35). This could be also explained by the structure of dentin in the apical region of human teeth with lower number of dentinal tubules (36).

There was an obvious relation between the bond strength values and that of the failure mode. The dominating cohesive failure demonstrated in groups II and III could be 
due to the effect of these irrigants that enhanced the bond strength of ActiV GP to the dentinal walls of the canals. This cohesive failure might be attributed to weakening in the gutta-percha when sialinated with coating (37) and the nonhomogeneous coating of glass ionomer particles on the surface of the ActiV GP cone leading to less favorable bonding (38). On the other hand, EDTA irrigation in group I decreased the bond strength of ActiV GP resulting in disruption of the sealer-dentin interface (adhesive failure). These findings agreed with Naser and Al-Zaka (15).

Differences of the results could also be attributed to the use of extracted human teeth which introduced variabilities (39). In addition, the push-out bond strength was revealed to be significantly higher in human root dentin compared to bovine root dentin.

On the other hand, other studies used bovine teeth as they claimed that bovine enamel and dentin gave bond strength values similar to that of human permanent teeth (40).

\section{CONCLUSIONS:}

Within the limitations of this study, it could be concluded that final irrigation with $\mathrm{CHX}$ or MTAD was found to be beneficial before obturation with ActiV GP. The root segment location had a significant influence on the bond strength. Stereomicroscopic evaluation revealed adhesive failure in EDTA and $\mathrm{NaOCl}$ groups, whereas cohesive failure predominated in MTAD and CHX groups.

\section{CONFLICT OF INTEREST:}

The authors declared that they have no conflicts of interest.

\section{ACKNOWLEDGMENTS:}

I would like to thank Zeinab Hassan, Mohamed Hamdy and Ayman Samy for the great effort and support throughout the study period.

\section{REFERENCES:}

1. Saber SE, Nagy MM, Schäfer E. Comparative evaluation of the shaping ability of Wave- One, Reciproc and OneShape single-file systems in severely curved root canals of extracted teeth. Int Endod J. 2015; 48:109-14.

2. Sena NT, Gomes BPFA, Vianna ME, Berber VB, Zaia AA, Ferraz CCR, et al. In vitro antimicrobial activity of sodium hypochlorite and chlorhexidine against selected single species biofilms. Int Endod J. 2006; 39:878-85.

3. Pérez-Heredia M, Ferrer-Luque CM, González-Rodríguez MP, Martín-Peinado FJ, González-López S .Decalcifying effect of $15 \%$ EDTA, $15 \%$ citric acid, $5 \%$ phosphoric acid and $2.5 \%$ sodium hypochlorite on root canal dentine. Int Endod J. 2008; 41:418-23.

4. Hülsmann M, Heckendorff M, Lennon A. Chelating agents in root canal treatment; mode of action and indications for their use. Int Endod J. 2003; 36:810-30.

5. White RR, Hays GL, Janer LR. Residual antimicrobial activity after canal irrigation with chlorhexidine. J Endod. 1997; 23:229-31.

6. Torabinejad M, Shabahang S, Aprecio RM. The antimicrobial effect of MTAD: an in vitro investigation. $\mathrm{J}$ Endod. 2003; 29:400-3.

7. Tay FR, Pashley DH. Monoblocks in root canals: a hypothetical or a tangible goal. J Endod. 2007; 33:391-8.
8. Wennberg A, Orstavik D. Adhesion of root canal sealers to bovine dentine and guttapercha. Int Endod J. 1990; 23:139.

9. Nagas E, Cehreli ZC, Durmaz V. Regional push out bond strength and coronal micro leakage of resilon after different light curing methods. J Endod. 2007; 33:1464-8.

10. Dogan H, Oalt S. Effects of chelating agents and sodium hypochlorite on mineral content of root dentin. J Endod. 2001; 27:578-80.

11. Uzunoglu E, Yilmaz Z, Erdogan O, Görduysus M. Final Irrigation Regimens Affect Fracture Resistance Values of Root-filled Teeth. J Endod 2016; 42:493-5.

12. Farag HA, Etman WM, Alhadainy HA, Darrag AM. Effect of different irrigating protocols on push out bond strength of Resilon/Epiphany obturation system. Tanta Dental Journal 2015; 12: 241-8.

13. Hashem AA, Ghoneim AG, Lutfy RA, Fouda MY. The effect of different irrigating solutions on bond strength of two root canal-filling systems. J Endod. 2009; 35:537-40.

14. Dinesh K, Murthy BVS, Narayana IH, Hegde S, Madhu KS, Nagaraja S. The Effect of $2 \%$ Chlorhexidine on the Bond Strength of Two Different Obturating Materials. J Contemp Dent Pract. 2014; 15: 82-5.

15. Naser SH, Al-Zaka IM. Push-out bond strength of different root canal obturation materials. J Bagh College Dentistry. 2013; 25: 14-20.

16. Razmi H, Bolharia B, Karamzadeh Dashti N, Fazlyab M. The Effect of Canal Dryness on Bond Strength of Bioceramic and Epoxy-resin Sealers after Irrigation with Sodium Hypochlorite or Chlorhexidine. Iran Endod J 2016; 11: 129-33.

17. Rocha AW, Andrade CD, Leitune VCB, Collares FM, Samuel SMW, Grecca FS, et al . Influence of Endodontic Irrigants on Resin Sealer Bond Strength to Radicular Dentin. Bull Tokyo Dent Coll. 2012; 53:1-7.

18. Dhingra A, Srivastava P, Chadda D, Banerjee S. Simplify your Endodontics with Single File Systems- Case Reports. JDMS. 2013; 6:44-51.

19. Teixeira CS, Alfredo E, Thome LH, Gariba-Silva R, SilvaSousa YT, Sousa-Neto MD. Adhesion of an endodontic sealer to dentin and gutta-percha: shear and push-out bond strength measurements and SEM analysis. J Appl Oral Sci. 2009; 17:129-35.

20. Ungor M, Onay EO, Orucoglu H. Push-out bond strengths: The Epiphany-Resilon endodontic obturation system compared with different pairings of Epiphany, Resilon, $\mathrm{AH}$ Plus and guttapercha. Int Endod J. 2006; 39:643-7.

21. Goracci C, Tavares AU, Fabianelli A, Monticelli F, Raffaelli O, Cardoso PC, et al. The adhesion between fiber posts and root canal walls: comparison between microtensile and pushout bond strength measurements. Eur J Oral Sci.2004; 112:353-61.

22. Attal JP, Asmussen E, Degrange M. Effects of surface treatment on the free surface energy of dentin. Dent Mater. 1994; 10:259-64.

23. Dogan Buzoglu H, Calt S, Gümüsderelioglu M. Evaluation of the surface free energy on root canal dentin walls treated with chelating agents and $\mathrm{NaOCl}$. Int Endod J. 2007; 40:1824.

24. Sly MM, Moore BK, Platt JA, Brown CE. Push-Out Bond Strength of a New Endodontic Obturation System (Resilon/Epiphany). J Endod. 2007; 33:160-2.

25. Mozayeni MA, Zadeh Y M, Paymanpour P, Ashraf H, Mozayani M. Evaluation of push-out bond strength of 
AH26 sealer using MTAD and combination of $\mathrm{NaOCl}$ and EDTA as final irrigation. Dent Res J. 2013; 10: 359- 63.

26. Ravikumar J, Bhavana V, Thatimatla C, Gajjarapu S, Reddy SGK, Reddy BR. The effect of four different irrigating solutions on the shear bond strength of endodontic sealer to dentin - An In-vitro study. J Int Oral Health. 2014; 6: 85-8.

27. Shokouhinejad N, Sharifian MR, Jafari M, Sabeti MA. Push-out bond strength of Resilon/Epiphany self-etch and guttapercha/AH26 after different irrigation protocols. J Endod. 2010; 110:88-92.

28. Singh S, Krishna S, Acharya SR, Rao PS, Ballal V. Comparison of antimicrobial efficacy of biopure MTAD and $2.5 \%$ sodium hypochlorite irrigation in infected root canals following single visit endodontics - An in vivo study. Endodontology 2009; 21:27Agrawal A, Paul B, Mantri Sh, Dube K. The Effect of Different Irrigation Regiments on the Push out Bond Strength of MTA Fillapex Sealer to Dentin. BJMMR 2015; 9: 1-8.

29. Perdigao J, Denehy GE, Swift EJ Jr. Effects of chlorhexidine on dentin surfaces and shear bond strengths. Am J Dent. 1994; 7:81-4.

30. Lalh MS, Titley KC, Torneck CD, Friedman S. Scanning Electron Microscopic Study of the Interface of Glass Ionomer Cement Sealers and Conditioned Bovine Dentin. J Endod 1999; 25: 743-6.

31. Baldissera R, Rosa RA, Wagner MH, Kuga MC, Grecca FS, Bodanezi A. Adhesion of Real Seal to

32. Human Root Dentin Treated with Different Solutions. Braz Dent J. 2012; 23: 521-6.

33. Nagas E, Uyanik MO, Eymirli A. Dentin moisture conditions affect the adhesion of root canal sealers. J Endod. 2012; 38:240-4.

34. Al-Hamed MJ, Fouda MY, Ahmed GM. Effect of different irrigates on the bond strength of bioceramic sealer to root canal dentin. Egypt Dent J. 2011; 57: 2269-75.

35. Torabinejad M, Khademi AA, Babagoli J, Cho Y, Johnson W, Bozhilov K, et al. A new solution for the removal of the smear layer. J Endod. 2003; 29:170-5.

36. Kaif M, Bissu R. Influence of irrigating solutions on pushout bond strenght of intraradicular posts to dentine. Int $\mathrm{J}$ Dent Sc 2016; 18: 73-81.

37. Elsheikh AM, Mohamed GE, Saba AA. Push out bond strength of glass ionomer-Impregnated gutta percha/glass ionomer sealer System to root canal dentin conditioned with Different endodontic irrigants. Eygpt Dent J. 2011; 57:2351-5.

38. Monticelli F, Sword J, Martin RL, Schuster GS, Weller RN, Ferrari M. Sealing properties of two contemporary singlecone obturation systems. Int Endod J. 2007; 40:374-85.

39. Perdigão J . Dentin bonding-variables related to the clinical situation and the substrate treatment. Detnal Mater. 2010; 26:24-37.

40. Nakamichi I, Iwaku M, Fusayama T. Bovine teeth as possible substitutes in the adhesion test. J Dent Res. 1983; 62:1076-81. 